Volume 3, Issue 3, July-September 2018, Pages: 270, DOI: http://dx.doi.org/10.19082/ah270

\title{
IN VITRO AND IN SILICO EXPLORATION OF THE HEMAGGLUTINATING ACTIVITY OF AN ANTITHROMBOTIC C- TYPE LECTIN ISOLATED FROM CERASTES CERASTES VENOM
}

\author{
SAOUD Samah, CHERIFI Fatah, LARABA-DJEBARI Fatima* \\ *Tel: +21321336076; Fax: +21321336077, Email: flaraba@hotmail.com, flaraba@usthb.dz
}

USTHB, Faculty of Biological Sciences; Laboratory of Cellular and Molecular Biology, BP 32 El-Alia, Bab Ezzouar, Algiers, Algeria

\section{TYPE OF ARTICLE: CONFERENCE ABSTRACT}

\begin{abstract}
In the present work, we report a structure-function characterization of the hemagglutinating activity of a C-type lectin purified from Cerastes cerastes venom. This molecule was shown to be a 34,597.62 Da polypeptide with 160 amino acids sequence. Cc-Lec 3D structure is organized into a homodimer cross-linked with a disulfide bridge and was predicted to have three alpha helices and seven beta strands for each monomer. Cc-Lec was able to agglutinate a wide spectrum of native erythrocytes, among them human group $\mathrm{O}, \mathrm{A}$ and $\mathrm{B}$ erythrocytes. Hemagglutination inhibition studies using bivalent ions and metal chelators EDTA, EGTA and 1.10phenanthroline showed the requirement of $\mathrm{Ca}^{2+}$ to each function of Cc-Lec. Moreover, its hemagglutinating activity was not abolished at high temperatures and was stable in basic $\mathrm{pH}$ range. The agglutination inhibitory assay in the presence of many carbohydrates revealed that this activity was high selectively inhibited by DLactose. These experimental data were in agreement with molecular docking studies. Hence, the determinant of human group B erythrocytes is linked to Cc-Lec by two hydrogen bonds; the first of them was established between fucose and $\mathrm{Asn}^{98}$, while the second was between galactose and Asn ${ }^{121}$. Cc-Lec interaction with the determinant of human group A erythrocytes was also through two hydrogen bonds linking determinant galactose with Cc-Lec residues Gly ${ }^{117}$ and Asn ${ }^{114}$. The current study contributes to further characterization of the newly purified lectin, especially as it showed promising biological activities which promote its use as a pharmacological tool in thrombosis diagnosis and therapy.
\end{abstract}

KEYWORDS: Cerastes cerastes, C-Type Lectin, Hemagglutination, Human erythrocytes, Molecular docking

\footnotetext{
Abstracts of Third International Conference on Health Sciences and Medical Technologies, October 2018, Tlemcen, Algeria (ICHSMT-18)

(C) 2018 The Authors. This is an open access article under the terms of the Creative Commons Attribution-NonCommercialNoDerivs License, which permits use and distribution in any medium, provided the original work is properly cited, the use is non-commercial and no modifications or adaptations are made.
} 